\title{
Local dispersal of juvenile bivalves: implications for sandflat ecology
}

\author{
Alf Norkko*, Vonda J. Cummings, Simon F. Thrush, Judi E. Hewitt, Terry Hume
}

National Institute of Water and Atmospheric Research, PO Box 11-115, Hamilton, New Zealand

\begin{abstract}
Dispersal has profound influences on population dynamics and is a key process maintaining spatial and temporal patterns. For many benthic marine invertebrates dispersal occurs primarily during the planktonic larval stages. It is now widely recognised that post-larval and juvenile stages of benthic invertebrate species can also exhibit high rates of dispersal. In particular, post-settlement dispersal has been demonstrated for many bivalve species. Despite this appreciation, no studies to date have analysed the direct dispersal rates and the spatial distribution of dispersing individuals in situ. We used a fluorescent stain for marking bivalves in vivo and a mark-and-recapture methodology to investigate dispersal patterns of post-larval and juvenile bivalves on a sandflat. Wave-induced energy dissipation on the seafloor was measured using a DOBIE wave gauge. Tracer sediment and bedload transport was used as a template for bivalve movement. The experiment was conducted over a short-time span $(60 \mathrm{~h})$ and encompassed spatial scales relevant to many sampling designs and manipulative experiments. Our results show that juvenile bivalves dispersed over scales of meters within one tidal cycle. Modelling the half-life of juvenile bivalve retention using radioactive decay equations provided insight into the local persistence of individuals. These models indicate a $50 \%$ turnover within an area of $0.25 \mathrm{~m}^{2}$ for post-larval $(<1 \mathrm{~mm})$ bivalves within the first $17.4 \mathrm{~h}$, whereas juvenile (1-4 mm) bivalves persist longer with a $50 \%$ turnover after $31.5 \mathrm{~h}$. Considering the very calm hydrodynamic conditions during the experiment, these dispersal rates are remarkable. Bivalve dispersal was decoupled from sediment bedload transport, illustrating the importance of active dispersal behaviour under the prevailing hydrodynamic conditions. Our results suggest that dispersal is potentially more important than mortality for the population dynamics of juvenile bivalves over small and meso spatial-time scales.
\end{abstract}

KEY WORDS: Bivalve dispersal · Post-settlement transport - Wind waves $\cdot$ Disturbance $\cdot$ Scale Sediment bedload transport $\cdot$ Intertidal sandflats

Resale or republication not permitted without written consent of the publisher

\section{INTRODUCTION}

Dispersal is an intrinsic characteristic of all organisms and has profound influences on the dynamics of populations (Hamilton \& May 1977, Palmer et al. 1996). The ability to disperse and escape from natural longterm environmental changes is crucial to the very persistence of species on micro-evolutionary time-scales (Holt 1990). Dispersal has broad implications in most fields of ecology (e.g. Kareiva 1986, Wiens et al. 1993,

*E-mail: a.norkko@niwa.cri.nz
Ims 1995) and has been described as the glue that keeps local populations together in a metapopulation (Hansson 1991). As pointed out by Dayton (1994) dispersal emerges as a key process maintaining spatial and temporal structure and as a unifying element of all levels of ecological organisation. For many benthic marine invertebrates extensive dispersal is considered to occur primarily during the planktonic larval stages, especially when large distances are concerned (e.g. Strathmann 1974, Jablonski 1986, Scheltema 1986), whereas dispersal during the post-settlement juvenile and adult stages has been believed to be less important. In soft sediment systems, bivalves and poly- 
chaetes are commonly numerical dominants but often the potential for emigration after primary settlement is ignored. As pointed out by Armonies (1994a), it is often assumed that local declines in population densities (i.e. over scales of sampling and experiments) may be ascribed to mortality, rather than to emigration. This static view of benthic invertebrates has for a long time been countered by observations that these animals exhibit regular tidal migrations (e.g. Ansell 1983, McLachlan 1983, Reise 1985, Beukema 1993). Spatfall does not necessarily terminate mobility of post-larval and juvenile stages of benthic invertebrate fauna. In particular, post-settlement dispersal has been demonstrated for many bivalve species (Baggerman 1953, Butman 1987, Beukema \& de Vlas 1989, Armonies 1992, 1994a,b, Günther 1992, Cummings et al. 1995, Commito et al. 1995a,b, Roegner et al. 1995, Jaklin \& Günther 1996, Hewitt et al. 1997a) over scales of 1 to $10^{4} \mathrm{~m}$ (Beukema \& de Vlas 1989). In fact, some bivalves, such as the ovoviviparous bivalve Gemma gemma, lack free swimming larvae altogether and only disperse as juveniles and adults (Commito et al. 1995b).

Intertidal sandflats, with high rates of sediment transport generated via the interacting tidal currents and wind waves, are dynamic environments for surface and near-surface dwelling juveniles. Consequently, the dispersal of post-settlement bivalves has been found to occur both entirely passively, associated with sediment bedload transport (Emerson \& Grant 1991, Commito et al. 1995a, Turner et al. 1997), and actively, through byssus-drifting in the water column (Sigurdsson et al. 1976, Beukema \& de Vlas 1989, Martel \& Chia 1991, Armonies 1992, Cummings et al. 1993, 1995, Bonsdorff et al. 1995). Post-settlement dispersal has important implications as it allows individuals to (1) move into areas more suitable for their successful development and growth (sensu Pulliam 1988, Beukema 1993), (2) escape adverse local conditions (Frid 1989, Pridmore et al. 1991) and (3) recolonise disturbed areas (Bonsdorff 1983, Savidge \& Taghon 1988, Smith \& Brumsickle 1989, Günther 1992, Thrush et al. 1992, Whitlatch et al. 1998, Beukema et al. 1999). Because of the high mobility of many benthic invertebrates, it is expected (or possible) that small-scale distribution patterns are dynamic and sometimes change on a daily or tidal basis. Movements over different temporal and spatial scales cause individuals to differ in both the biotic interactions and resource-levels they experience. Local inter- and intra-specific interactions are likely to play a lesser role when dispersal rates are high (Kotliar \& Wiens 1990, Schneider et al. 1997, Thrush et al. 2000).

In marine systems, very few quantitative studies have been conducted on either rates of dispersal or the spatial and temporal scales over which juvenile animals move (Howard 1985) and, in marine soft sediments in particular, the role of dispersal in patch dynamics remains poorly understood (Commito et al. 1995a). To a large extent this is due to the small and cryptic nature of most juvenile benthic invertebrates, which makes them difficult to study. Hence, patterns of dispersal are generally inferred from studies on recruitment (e.g. Bonsdorff 1983, Smith \& Brumsickle 1989, Günther 1992, Thrush et al. 1996), overall dispersal rates and fluxes (e.g. Commito et al. 1995b, Turner et al. 1997) or spatial patterns (e.g. Armonies 1996, Hewitt et al. 1996, 1997). There are very few studies in which juvenile invertebrates have been tracked directly in the field (see Levin 1990 for a review), and there have been no attempts to identify the movement of individuals. Thus, while we often know which species move, and sometimes how they move, generally we have little idea of how far, or the proportion of the local population they represent over space and time scales commonly exploited in sampling soft sediment macrofauna. Quantitative studies on the dispersal of species are imperative if we are to understand the dynamics of populations in time and space (Wiens et al. 1993) and interpret recovery patterns after disturbances (Smith \& Brumsickle 1989, Thrush et al. 1996, Shull 1997, Whitlatch et al. 1998). The objectives of this study were to directly assess the dispersal rates of marked juvenile bivalves. We used a fluorescent stain to mark bivalves in vivo and a mark-and-recapture method to investigate the dispersal patterns of postlarval and juvenile bivalves. Bedload transport of sediment at the site was used as a template for bivalve movement (Commito et al. 1995a,b, Grant et al. 1997, Turner et al. 1997). In this paper we study the shortterm dispersal dynamics occurring over small spatial scales (i.e. the scales at which many field experiments are conducted). We used displacement (percent leaving an area) and diffusion rates (distance travelled or numbers reaching a certain distance over time), combined with physical measurements, to investigate the dispersal distance of bivalves and sediment, and compared our observations with predicted calculations of a random walk model.

\section{MATERIALS AND METHODS}

Study site. This study was conducted on an exposed intertidal sandflat off Wiroa Island in Manukau Harbour, New Zealand (37 $01.3^{\prime} \mathrm{S}, 174^{\circ} 49.2^{\prime} \mathrm{E}$ ) from 12 to 14 February 1997 (Fig. 1). The sandflat fauna is dominated by bivalves, with the tellinid Macomona liliana Iredale being the most common species (see Pridmore et al. 1990 for a detailed description of the Wiroa Island 
macrobenthic community). The study site is situated at about mid-tide level, and is exposed to the prevailing southwesterly winds, which produce waves 10 to $30 \mathrm{~cm}$ in height and rework sediments to a depth of 1 to $3 \mathrm{~cm}$ (Dolphin et al. 1995), the depths where juvenile bivalves reside. The harbour is mesotidal, having semidiurnal tides with mean neap and spring tidal ranges of 2.0 and $3.4 \mathrm{~m}$, respectively. The topographic features of this largely homogeneous sandflat include small ripples created by waves and currents that vary on a daily basis, but most typically have a wavelength of 3 to $10 \mathrm{~cm}$ and an amplitude of 0.5 to $1 \mathrm{~cm}$ (Dolphin et al. 1995). During the summer months, the sediments are frequently disturbed by the eagle ray Myliobatis tenuicaudatus (Hector), which creates feeding pits 20 to $30 \mathrm{~cm}$ in diameter and 10 to $15 \mathrm{~cm}$ deep. The surface sediments are comprised of 92 to $97 \%$ sand (very well sorted sands; mean grain size of $2.74 \phi \pm 0.12$ ), 0 to $3 \%$ gravel (mainly shell hash) and 0.2 to $3.4 \%$ silts and clays (Bell et al. 1997). At the site, tidal currents alone are not strong enough to exceed the critical threshold values for particle sediment entrainment but, in combi-

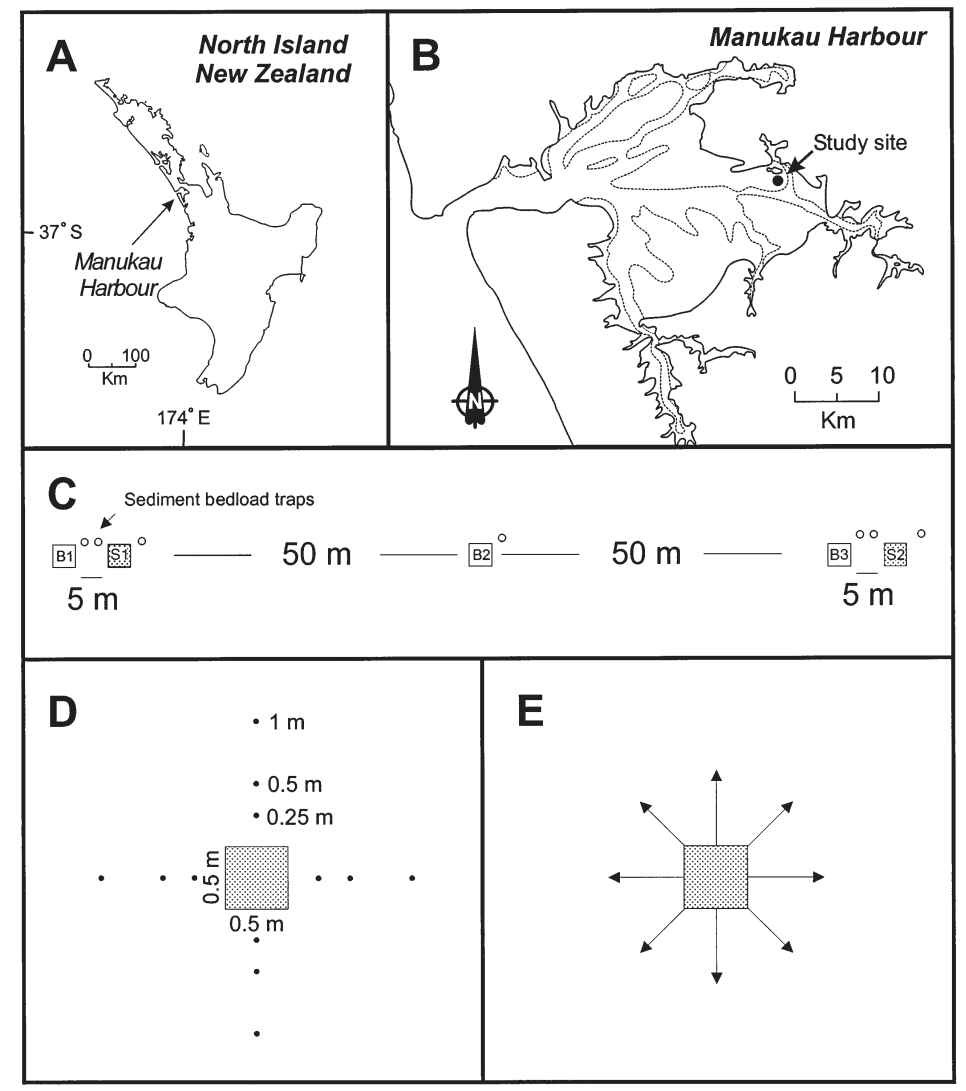

Fig. 1. Location and experimental design at the study site and the sampling strategy. (A) Position of Manukau Harbour in the North Island of New Zealand; (B) the study site; (C) arrangement of biological (white, B1 to B3) and physical (grey, S1 to S2) quadrats; (D) locations of samples for juvenile bivalves; and (E) visual observations of sediment dispersal nation with even small wind waves, sediment transport is readily initiated on the sandflat (Bell et al. 1997).

Staining of bivalves and sediment. Fluorescein (100 $\mathrm{mg} \mathrm{l}^{-1}$ seawater) was used to stain infauna. Stained individuals glowed more brightly than unstained ones when examined microscopically under an ultraviolet light. Preliminary trials showed that concentrations of $100 \mathrm{mg}$ of fluorescein $\mathrm{l}^{-1}$ of seawater were sufficient to stain infauna. Trials were conducted in the laboratory over $6 \mathrm{~d}$ to test for any adverse effects of fluorescein as a marking technique on behavioural characteristics (e.g. burrowing and drifting) as well as on survivorship of juvenile bivalves. Trials were conducted in aquaria using sediment from the study site. No differences in behaviour or survivorship were detected.

Rocket red fluorescent powder (Sterling Industrial Colours Ltd), with a dominant wavelength in the emission spectrum of $614.2 \mathrm{~nm}$, was used to stain the sediments. Sediment was collected from the Wiroa sandflat, washed in freshwater and dried. The appropriate quantities of dried sediment, rocket red powder, laquer (adhesive) and thinners were mixed using a Throtnungler which consists of a rotating plastic drum with baffles and loose steel rollers on the inside, which stop the sediment grains from sticking together. The drum is rotated with hot air blowing through it until the mixture is dry. Stained sediments can be identified in the dark under a UV-light, thus making it possible to track stained sediments in the field at night.

Experimental design. The experiment was designed to examine the dispersal of marked juvenile bivalves compared with that of marked sediment particles. Three 'biological' quadrats and 2 'sediment' quadrats were established in the mid intertidal area of the Wiroa Island sandflat (Fig. 1). All quadrats were sampled on the first, third, and fifth low tide period following the setup of the experiment (after approximately 12, 36 and $60 \mathrm{~h}$ ). These sampling times are hereafter referred to as $\mathrm{T} 1, \mathrm{~T} 2$ and $\mathrm{T} 3$, respectively. $\mathrm{T} 0$ denotes the start of the experiment. A DOBIE wave gauge was deployed to measure wave climate and sediment bedload traps were deployed to measure bedload transport. The experiment was conducted over a mean spring tide. Information on tidal current velocities from the study site were obtained from Bell et al. (1997). Wind data were collected from the adjacent Auckland International Airport (see 'Results').

Biological quadrats: A metal quadrat $(50 \times$ $50 \mathrm{~cm} \times 20 \mathrm{~cm}$ deep) was pushed $15 \mathrm{~cm}$ into the sediment so that $5 \mathrm{~cm}$ protruded above the sediment surface. The fauna present in each quadrat was stained by pouring $4 \mathrm{l}$ of fluorescein $(100 \mathrm{mg}$ 
$\mathrm{l}^{-1}$ seawater) into the quadrat and leaving it for about $3 \mathrm{~h}$. The metal quadrat was removed just as the flooding tide reached it, and a core sample $(5 \mathrm{~cm}$ diameter, $2 \mathrm{~cm}$ deep) was taken from one corner of the quadrat (sampling occasion $=\mathrm{T} 0$ ). Three quadrats $(\mathrm{B} 1$ to B3) were set out along a line parallel to the shore $50 \mathrm{~m}$ apart (Fig. 1C).

Sediment quadrats: A $50 \times 50 \mathrm{~cm}$ area was marked and excavated to $2 \mathrm{~cm}$ depth and replaced with prewetted rocket-red-dyed tracer sediment. Two sediment quadrats were established (S1 and S2) and each was paired with a biological quadrat (Fig. 1c).

Measurements of hydrodynamic and wind conditions: A DOBIE wave gauge was deployed to provide time series data on wave orbital speed at the bed during the experiment (see Thrush et al. 2000, and http:// www.niwa.cri.nz/instrument_systems/dobie.html for a detailed description). DOBIE measures waves and water depth (and thus immersion time) by measuring water pressure. It consists of a pressure sensor interfaced to a controller/logger and a battery power supply, all of which is contained within a small pressure case. DOBIE measured pressure in bursts, with each burst consisting of 2048 data points at a sampling interval of $0.2 \mathrm{~s}$. The interval between bursts was $30 \mathrm{~min}$. Linear wave theory (e.g. see Kinsman 1984) was used to compute the orbital speed at the bed $\left(U_{b}, \mathrm{~cm} \mathrm{~s}^{-1}\right)$ corresponding to the significant wave height, mean spectral period and mean water depth (see Green \& Black 1999 for details on converting burst pressure data into estimates of $U_{b}$ ). Since the time-averaged dissipation of wave energy by bed friction is proportional to $U_{b}{ }^{3}$ (Nielsen 1992), we used $U_{b}^{3}$ to characterize energy dissipation by waves at the site. We characterized disturbance to the seabed by waves as percentage of the total time waves were present at the site; average $U_{b}{ }^{3}$ (e.g., total $U_{b}{ }^{3}$ divided by number of bursts when waves were present); maximum $U_{b}{ }^{3}$ (measured from a single burst) and the ratio maximum:average $U_{b}{ }^{3}$.

Bedload traps: Five replicate bedload traps $(4 \mathrm{~cm}$ diameter, $50 \mathrm{~cm}$ deep) were deployed on each sampling occasion during the experiment to determine the gross amount of sediment moving (see Commito et al. 1995b; Fig. 1c). The traps were sampled/deployed at the same intervals as the biological samples, i.e. 12, 36 and $60 \mathrm{~h}$ after the initiation of the experiment. Any fauna collected in each trap was removed and the sediment oven-dried at $60^{\circ} \mathrm{C}$ for $48 \mathrm{~h}$. Sediment transport rates were derived and expressed as $\mathrm{kg}$ dry mass $\mathrm{m}^{-2}$ $\mathrm{d}^{-1}$ (Grant et al. 1997).

Experimental sampling and treatment of samples. The maximum distance tracer sediment had moved away from each of the sediment quadrats on each sampling occasion was determined at night using a portable ultraviolet light. Our staining technique was highly efficient, and by careful observation even individual fluorescing grains could be detected. The distance the sediment had dispersed was measured in 8 directions separated by $45^{\circ}$ around each quadrat (Fig. 1e).

Each quadrat and the surrounding area were sampled quantitatively for bivalves and tracer sediments as follows: a core sample (5 $\mathrm{cm}$ diameter, $2 \mathrm{~cm}$ deep) was collected from inside the quadrat, from a different quarter of the quadrat on each occasion. Core samples were also taken from outside the quadrat in each of 4 directions at increasing distances $(0.25,0.50$ and $1.0 \mathrm{~m})$ from the quadrat edge (Fig. 1d). At T3, core samples were also obtained from the maximum distance that tracer sediment was observed to have moved from the paired sediment quadrat (see below). All core samples were frozen and kept in the dark until they could be processed.

Biological cores were sieved on a $250 \mu \mathrm{m}$ mesh, and the material retained on the mesh was sorted under a stereo microscope to remove all bivalves. Bivalves were then identified and assigned to 1 of 2 size classes, viz. post-larval bivalves $(<1 \mathrm{~mm})$ and other juvenile bivalves (1-4 mm). For the purpose of doing speciesspecific analyses, we also noted the abundances of the 2 most commonly found bivalve species on the sandflat, the tellinid Macomona liliana Iredale and the venerid Austrovenus stutchburyi (Gray). The bivalves were then examined for fluorescence under UV excitation (BP 450 to $490 \mathrm{~nm}$ excitation, LP 520 barrier filter, FT 510 dichromatic beam splitter) using a Leica epifluorescence compound light microscope.

The amount of tracer sediment contained in each of the cores from in and around the sediment quadrats was determined using a spectrophotometric method. The sediment was rinsed in freshwater and dried at $100^{\circ} \mathrm{C}$ for $6 \mathrm{~h}$. The tracer was extracted in pure acetone, and absorption measured at $560 \mathrm{~nm}$ using a spectrophotometer. After establishing a linear relationship between absorbed colour and the mass of tracer sediment, the samples were subsampled for extraction of colour. This method worked well with the naturally well sorted and homogeneous sediments present at the study site, as the surface area (and therefore colour concentration) of the sand grains is reasonably consistent. We could thus obtain a quantitative estimate of dispersal of the tracer sediment by measuring the colour concentration in the sediment samples.

Measurements of bivalve and sediment fall velocity. Fall velocities $\left(\mathrm{cm} \mathrm{s}^{-1}\right)$ of dead individuals of Macomona liliana and Austrovenus stutchburyi, and sand from the Wiroa sandflat were measured in a $6 \mathrm{~cm}$ diameter settling chamber. The bivalves ranged in size from 0.5 to $4 \mathrm{~mm}$ and the sand had a median grain size of $167 \mu \mathrm{m}$. Dead individuals with closed shells were 
used in order to determine their passive fall velocity. The bivalves were killed by submerging them briefly in a formalin solution. Individual bivalves and sand grains were pre-wetted and released just below the water surface and their descent timed over a distance of $34 \mathrm{~cm}$. Measurements were made in seawater (32\%) at $20^{\circ} \mathrm{C}$.

Numerical and statistical analyses. We investigated both the displacement of bivalves within the experimental plots and the consequent dispersal outside the plot after displacement. The displacement of bivalves from the biological plots was modelled by non-linear regression analysis. The data for the $<1 \mathrm{~mm}$ and 1-4 $\mathrm{mm}$ size-classes and the total number of bivalves $(<4 \mathrm{~mm})$, were fitted to a non-linear equation of a onephase exponential decay (law of radioactive decay; Rutherford 1900, Weidner \& Sells 1973) in order to describe the gradual displacement of bivalves as a function of time and to calculate half-lives of bivalves residency within the experimental plots:

$$
N=N_{0} \exp ^{-k t}
$$

where $N_{0}$ is the initial number of particles (bivalves) which decay (are displaced) as a function of time $t$ and $k$ is the disintegration constant. Following this, the half-life of the particle (bivalve) is $0.69 / k$. The data were constrained to fit within the range of the data with a total span of 100 and a fixed plateau of 0 , i.e. the function was forced towards a $100 \%$ displacement of the bivalves. From this fitting, the disintegration constant $(k)$ and estimates of half-lives could be produced.

Based on rates of displacement, survivorship curves (measuring the number of recaptured bivalves) for post-larvae $(<1 \mathrm{~mm})$ and juveniles $(1-4 \mathrm{~mm})$ were compared with a log-rank test (Mantel-Haenzel test using the programme GraphPad Prism 2.0). Patterns of bivalve and sediment movement outside the quadrats were compared using chi-square tests (Zar 1984). After testing for normality and homogeneity of variances, bivalve densities in the experimental plots over time were analysed using a non-parametric Kruskal-Wallis. All data are presented as the mean \pm standard error. A random walk model (Okubo 1980) was used to predict dispersal by the bivalves. Diffusion rates were calculated for the $<1 \mathrm{~mm}$, the 1-4 $\mathrm{mm}$ size-class bivalves, and all bivalves $<4 \mathrm{~mm}$, assuming the number of bivalves leaving the stained quadrats over time followed a normal distribution with a mean of 0 and a standard deviation equal to $\sigma^{2} t$ (where $\sigma^{2}=$ diffusion rate in $\mathrm{cm}$ $\mathrm{h}^{-1}$ and $t=$ time in $\mathrm{h}$ ). A diffusion rate was calculated for the 12, 36 and $60 \mathrm{~h}$ time periods and then averaged. This diffusion rate was then used to calculate the mean time taken for a particle executing ordinary Brownian motion to reach $25,50,100,200$ and $500 \mathrm{~cm}$ (e.g. crossing time) using the following formula.
Crossing time $=a^{2} / \sigma^{2}$

where $a=$ distance. This crossing time was then converted into tidal cycles by dividing by the immersion time. Median distances that should be travelled by the bivalves over the sampling times were also predicted using

$$
P(Y(t)<y)=2 \Phi\left(\frac{y}{\sigma \sqrt{ } t}\right)-1=0.5
$$

where $y=$ median distance travelled in time $t$ and $\Phi=$ cumulative distribution function of the standard normal distribution.

\section{RESULTS}

\section{Hydrodynamic conditions and sediment transport}

Wind data are presented only for the time period when the study site was immersed. Total immersion time over the $60 \mathrm{~h}$ study period was $21.5 \mathrm{~h}$, or approximately $36 \%$ of the time. Maximum water depth decreased over time from $1.04 \mathrm{~m}$ over the first tidal cycle to $0.63 \mathrm{~m}$ over the last tidal cycle (Table 1). Overall, weather conditions were calm during the study period. Over the $12 \mathrm{~h}$ period after initiation of the experiment (T1), light westerly winds averaging $6.8 \mathrm{~m} \mathrm{~s}^{-1}$ dominated and produced only small waves with maximum significant wave heights of $0.15 \mathrm{~m}$, an average significant wave height of $0.11 \mathrm{~m}$ and an average wave period of $2.1 \mathrm{~s}$ (Table 1). Over the next $24 \mathrm{~h}$ (T2), very calm conditions prevailed with only light winds and no waves. Winds increased again during the latter half of the last $24 \mathrm{~h}$ period (T3) to speeds similar to those in T1, with light winds from the WSW. Over the last $24 \mathrm{~h}$ period, the wave climate matched that of T1. Despite these relatively calm weather conditions, substantial gross bedload sediment transport was recorded using the bedload traps in the time-periods when waves were present (i.e. T1 and T3; Table 1). This further underlines the importance of wind waves in triggering sediment transport. Tidal currents at the study site only reach a maximum of $22 \mathrm{~cm} \mathrm{~s}^{-1}$ at $0.3 \mathrm{~m}$ above the bed during spring-tide ebb flows (Bell et al. 1997). The critical threshold bed shear velocities $\left(u *_{\mathrm{cr}}\right)$ for the fine sand (grain size $=150 \mu \mathrm{m}$ ) found at the study site range from 1.12 (Miller et al. 1977) to $1.22 \mathrm{~cm} \mathrm{~s}^{-1}$ (van Rijn 1993). According to Bell et al. (1997), these threshold values convert to a depth-averaged current velocity of 28 to $30 \mathrm{~cm} \mathrm{~s}^{-1}$ at $1 \mathrm{~m}$ depth. Tidal currents at the study site are always less than this and therefore fail to entrain material from the bed in the absence of wind waves. Median wave heights in the area are $0.09 \mathrm{~m}$, well exceeding the height necessary to induce initial motion of bottom sediments (i.e. $>0.06 \mathrm{~m}$ ), hence the sediments are frequently mobilised by waves and transported by currents (Dolphin et al. 1995, Bell et al. 1997). 
Table 1. Wind and hydrodynamic conditions and sediment transport during the study period measured when the site was immersed. T1 $=12 \mathrm{~h}$ following experimental setup; T2 = $36 \mathrm{~h}$ after; T3 $=60 \mathrm{~h}$ after. Note that T2 and T3 each contain 2 tidal cycles. $U_{b}{ }^{3}=$ the cube of orbital wave speed at the bed (measure of energy dissipation). Distances of sediment transport are based on visual observations of the maximum transported distance of fluorescent tracer sediment

\begin{tabular}{|c|c|c|c|c|c|}
\hline \multirow[b]{2}{*}{ Tidal cycle following experimental start: } & \multirow{2}{*}{$\begin{array}{c}\mathrm{T} 1(0-12 \mathrm{~h}) \\
1\end{array}$} & \multicolumn{2}{|c|}{ T2 (12-36 h) } & \multicolumn{2}{|c|}{ T3 $(36-60 \mathrm{~h})$} \\
\hline & & 2 & 3 & 4 & 5 \\
\hline \multicolumn{6}{|l|}{ Wind conditions: } \\
\hline Prevailing direction & $\mathrm{W}$ & ESE & N-NNE & E & WSW \\
\hline Duration (h) & 4 & 5 & 4 & 5 & 5 \\
\hline Averaqe speed $\left(\mathrm{m} \mathrm{s}^{-1}\right)$ & $6.8 \pm 0.7$ & $2.0 \pm 0.6$ & $3.2 \pm 0.6$ & $2.1 \pm 0.3$ & $6.3 \pm 0.3$ \\
\hline Maximum speed $\left(\mathrm{m} \mathrm{s}^{-1}\right)$ & 7.7 & 3.1 & 5.1 & 3.1 & 6.7 \\
\hline Immersion time $(\mathrm{h})$ : & 4.5 & 4.5 & 4.5 & 4 & 4 \\
\hline Maximum depth (m): & 1.04 & 0.86 & 0.81 & 0.67 & 0.63 \\
\hline \multicolumn{6}{|l|}{ Wave conditions: } \\
\hline Maximum significant height (m) & 0.15 & 0 & 0 & 0 & 0.12 \\
\hline Average significant height (m) & $0.11 \pm 0.03$ & 0 & 0 & 0 & $0.08 \pm 0.04$ \\
\hline Average period (s) & $2.1 \pm 0.4$ & 0 & 0 & 0 & $1.9 \pm 0.5$ \\
\hline$U_{b}{ }^{3}$ - cumulative (total, $\mathrm{cm}^{3} \mathrm{~s}^{-3}$ ) & $2.172 \times 10^{-2}$ & 0 & 0 & 0 & $2.239 \times 10^{-2}$ \\
\hline$U_{b}^{3}$-average $\left(\mathrm{cm}^{3} \mathrm{~s}^{-3}\right)$ & $2.487 \times 10^{-3}$ & 0 & 0 & 0 & $2.800 \times 10^{-3}$ \\
\hline$U_{b}^{3}-$ maximum $\left(\mathrm{cm}^{3} \mathrm{~s}^{-3}\right)$ & $7.211 \times 10^{-3}$ & 0 & 0 & 0 & $5.053 \times 10^{-3}$ \\
\hline$U_{b}{ }^{3}$-maximum/average & 2.987 & 0 & 0 & 0 & 1.805 \\
\hline \multicolumn{6}{|l|}{ Sediment transport } \\
\hline Bed load $\left(\mathrm{kg} \mathrm{m}^{-2} \mathrm{~d}^{-1}\right)$ & $108.3 \pm 15.9$ & \multicolumn{2}{|c|}{$0.6 \pm 0.0$} & \multicolumn{2}{|c|}{$137.1 \pm 27.3$} \\
\hline $\begin{array}{l}\text { Observed maximum distance } \\
\text { from plot edge }(\mathrm{cm})\end{array}$ & $135 \pm 13$ & \multicolumn{2}{|c|}{$153 \pm 11$} & \multicolumn{2}{|c|}{$233 \pm 10$} \\
\hline
\end{tabular}

Visual detection of tracer sediment at night-time showed that the average maximum spread away from the quadrat edge was $135 \mathrm{~cm}$ over the first $12 \mathrm{~h}$ (T1),

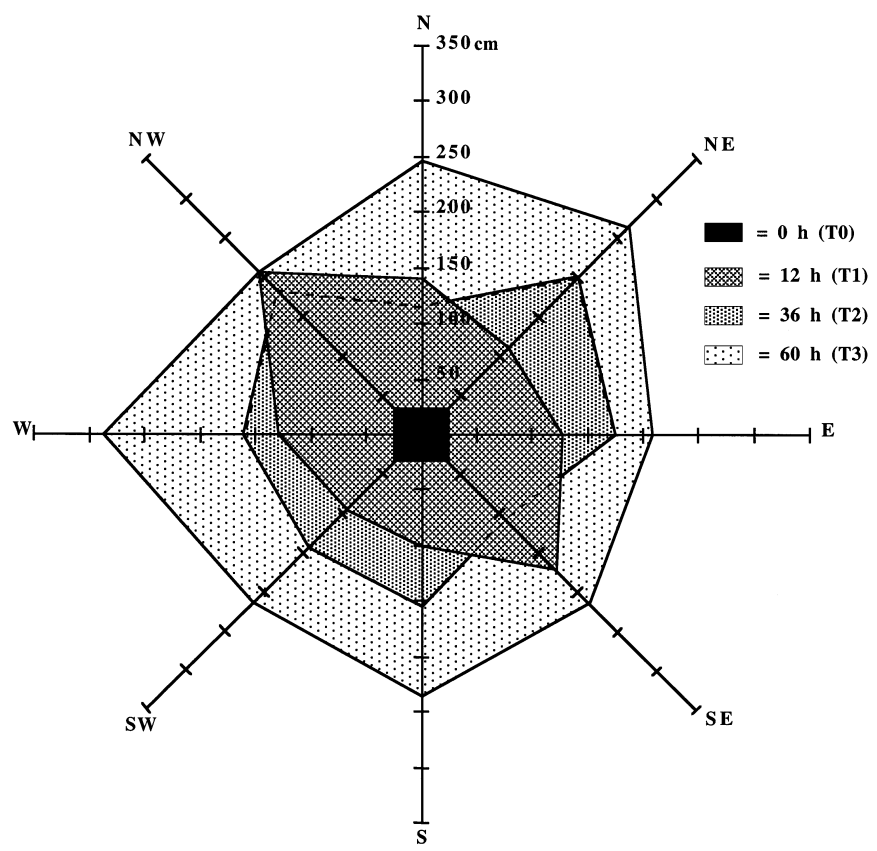

Fig. 2. Maximum distance $(\mathrm{cm})$ that tracer sediment was observed from the quadrat edges during the experiment. Distances are average values for sediment quadrats S1 and S2 increased slightly to $153 \mathrm{~cm}$ over the second $24 \mathrm{~h}$ period (T2) and increased considerably to $235 \mathrm{~cm}$ over the last $24 \mathrm{~h}$ period (T3). This pattern matched the physical regime and the pattern of sediment bedload transport (Table 1). Visual observations and chi-square tests of the distribution pattern of sediments did not indicate any directional transport of sediments for either quadrat on any sampling date. Data from sediment quadrats S1 and S3 (Fig. 1c,e) were therefore averaged over each direction for each sampling time (Fig. 2). Net sediment-diffusion rates (calculated on observed spread) were low, ranging between 3.4 and $11.2 \mathrm{~cm} \mathrm{~h}^{-1}$ over the study period. This is in contrast to the high bedload transport measured using the traps. It is therefore apparent that sediment is moved back and forth over each tidal cycle with little net directional transport.

Tracer sediment concentrations along the 4 different axes over time are expressed as absorbance $(\lambda) \mathrm{g}^{-1}$ of sediment, thus reflecting the amount of tracer sediment present in each core sample. Chi-square analysis of absorbance along each axis (direction) over time did not reveal any specific directional transport or diffusion of tracer sediment (i.e. there was no net-transport in any given direction), and chi-square values were low, ranging between 0.061 and 1.498 in T1 and T2 $\left(\chi^{2}-\right.$ crit. $\left.\mathrm{p}=0.05=5.991\right)$. Similarly at T3, values ranged between 0.120 and $1.466\left(\chi^{2}-\right.$ crit. $\left._{\mathrm{p}=0.05}=7.815\right)$, show- 
Table 2. Variations in juvenile bivalve densities over time inside experimental plots (ind. $\mathrm{m}^{-2} \pm \mathrm{SE}$ ), and levels of significance (Kruskal-Wallis, K-W) for comparisons among different time periods. T0 = start of the experiment; 1 = $12 \mathrm{~h}$ following experimental setup; T2 $=36 \mathrm{~h}$ after; $\mathrm{T} 3=60 \mathrm{~h}$ after

\begin{tabular}{|lcrrrr}
\hline Size-classes & T0 & T1 & T2 & T3 \\
\hline Total $(<4 \mathrm{~mm})$ & $2207 \pm 1180$ & $3565 \pm 882$ & $3395 \pm 449$ & $3820 \pm 1040$ \\
Post-larvae $(<1 \mathrm{~mm})$ & $1698 \pm 1180$ & $2207 \pm 612$ & $2716 \pm 740$ & $3310 \pm 623$ \\
Juveniles $(1-4 \mathrm{~mm})$ & $509 \pm 0$ & $1358 \pm 339$ & $679 \pm 339$ & $509 \pm 416$ & $\mathrm{p}=0.7127$ \\
& & & $\mathrm{p}=0.2280$ \\
\hline
\end{tabular}

ing a lack of pattern for transport in any given direction. The data from the 4 different directions were therefore pooled with increasing distance from the quadrat, i.e. at the fixed sampling distances 25, 50 and $100 \mathrm{~cm}$. On the last occasion (T3), the maximum observed average distance was also sampled. The mean distance sediment was observed to disperse was $243 \pm$ $62 \mathrm{~cm}$ at T3 (Fig. 2; min: $165 \mathrm{~cm}$; max:

$345 \mathrm{~cm}$ ). Successively lower concentrations were recorded with increasing distance from the quadrat (Fig. 3). This pattern was significant at T2 and T3 (linear regression; $\mathrm{r}^{2}=0.321, \mathrm{p}=0.0039$ and $\mathrm{r}^{2}=0.238$, $\mathrm{p}=0.0046$ for $\mathrm{T} 2$ and $\mathrm{T} 3$, respectively). Fig. 3 also shows a higher relative absorbance recorded at $25 \mathrm{~cm}$ on the second sampling occasion (T2); possibly because very low rates of sediment transport over this time-period resulted in a higher concentration of tracer sediment being retained in the proximity of the quadrat.

\section{Bivalve density/biological quadrats}

A total of 7 juvenile bivalve species were collected: Macomona liliana, Austrovenus stutchburyi, Hiatula

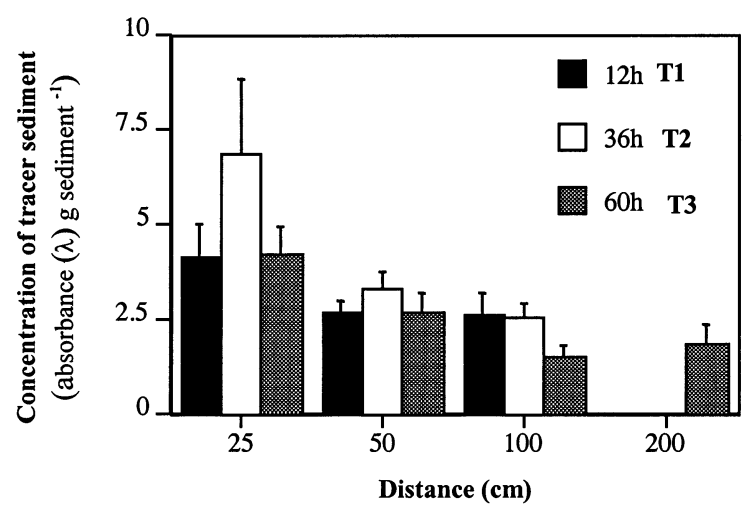

Fig. 3. Quantitative estimates of diffusion of tracer sediment from the quadrat edges. Concentrations are average values $(\bar{x} \pm \mathrm{SE})$ for sediment quadrats $\mathrm{S} 1$ and $\mathrm{S} 2$ and pooled over all directions siliquens, Nucula hartvigiana Pfeiffer, Mactra ovata (Gray), Arthritica bifurca (Webster) and an undetermined mytilid. Of all the juvenile bivalve species recorded, the tellinid $M$. liliana comprised $53 \%(\mathrm{n}=301)$ and the cockle A. stutchburyi $33 \%(\mathrm{n}=187)$ of the bivalve community. No significant changes in bivalve densities were recorded (all taxa, $<4 \mathrm{~mm}$ ) over time inside the experimental quadrats (Table 2). Densities within the quadrats were similar to those recorded outside the experimental quadrats (pooled data of all samples; 3600), indicating low disturbance by the set-up of the experiment. Not enough individuals of Macomona and Austrovenus were collected in samples inside the biological quadrats to allow for a species-specific analysis of diffusion rates. All bivalve species from inside the quadrats were therefore pooled and separated into post-larvae ( $<1 \mathrm{~mm}$ ) and juveniles (1-4 mm). However, because of the higher number of samples taken outside, enough bivalves were collected for a species-specific analyses of dispersal patterns.

\section{Displacement and diffusion rates of juvenile bivalves from experimental plots}

Based on previous experiences of the dynamic Wiroa Island sandflat, high rates of dispersal of the juvenile bivalves were expected. We predicted that dispersal of juvenile bivalves $<4 \mathrm{~mm}$ would be age and sizedependent. This was confirmed by the fall velocity measurements of bivalves and of sand. Fall velocities increased with bivalve size in all cases, and measurements also showed differences between species of bivalve (Table 3). Given the slower fall velocities of 


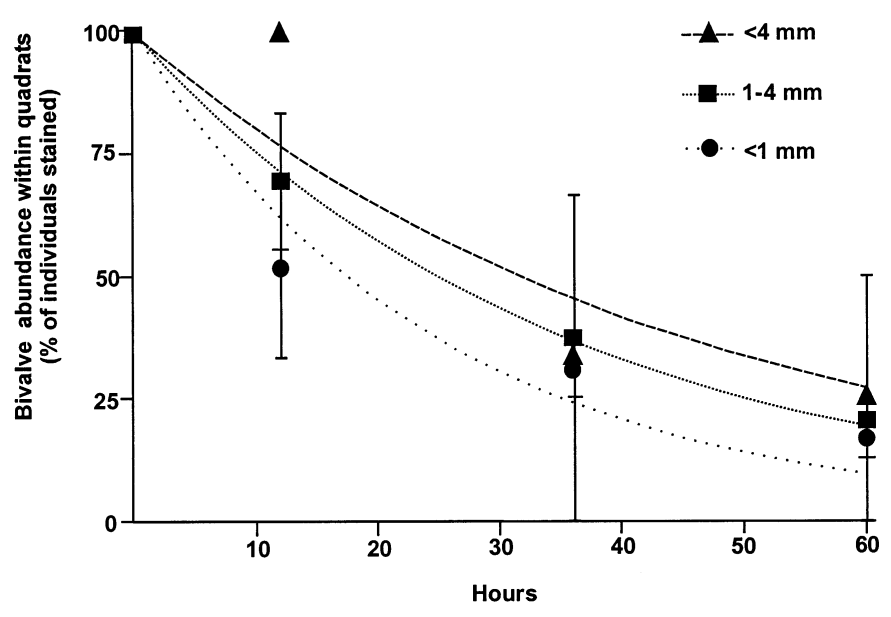

Fig. 4. Decay of abundance of stained bivalves from experimental plots measured as the mean percent stained individuals over time. $<1 \mathrm{~mm}=$ post-larvae; $1-4 \mathrm{~mm}=$ juveniles; $<4 \mathrm{~mm}=$ total (post-larvae and juveniles combined)

smaller size classes, post-larval bivalves $(<1 \mathrm{~mm})$ could be expected to exhibit higher dispersal rates than the slightly larger 'juveniles' (1-4 mm).

Despite the calm weather conditions over the time of the experiment (Table 1), high displacement rates were recorded (Fig. 4). Differences in displacement rates of the 2 size-classes as a function of time were tested using a log-rank test for comparisons of survival curves (Table 4). No significant differences $(p<0.05)$ were detected between the proportion of stained postlarvae and juveniles (Mantel-Hanzel test; one-tailed

Table 4. Displacement of juvenile bivalves over the $60 \mathrm{~h}$ study period fitted to a non-linear regression equation of exponential decay

\begin{tabular}{|c|c|c|c|}
\hline & $\begin{array}{c}\text { Total } \\
(<4 \mathrm{~mm})\end{array}$ & $\begin{array}{l}\text { Post-larvae } \\
\text { (<1 mm) }\end{array}$ & $\begin{array}{l}\text { Juveniles } \\
(1-4 \mathrm{~mm})\end{array}$ \\
\hline \multicolumn{4}{|c|}{ Non-linear regression } \\
\hline Span & 100 & 100 & 100 \\
\hline Plateau & 0 & 0 & 0 \\
\hline$k$ & 0.02795 & 0.03982 & 0.02199 \\
\hline Half-life (h) & 24.8 & 17.4 & 31.5 \\
\hline \multicolumn{4}{|l|}{ Standard error } \\
\hline$k$ & \pm 0.00473 & \pm 0.00788 & \pm 0.00797 \\
\hline \multicolumn{4}{|l|}{ Goodness of fit } \\
\hline $\mathrm{df}$ & 10 & 10 & 10 \\
\hline $\mathrm{r}^{2}$ & 0.8150 & 0.7873 & 0.5335 \\
\hline SS & 2222 & 2783 & 9967 \\
\hline \multicolumn{4}{|l|}{ Residuals } \\
\hline p-value & 1.000 & 0.4286 & 0.7143 \\
\hline $\begin{array}{l}\text { Deviation from } \\
\text { model }\end{array}$ & ns & ns & ns \\
\hline
\end{tabular}

$\mathrm{p}$-value $=0.0720, \chi^{2}=2.156$ ), although a tendency for higher 'survivorship' (i.e. less displacement) of 1-4 mm bivalves was indicated (Table 4). The data for the $<1 \mathrm{~mm}$ and 1-4 mm size-classes, and the total number of bivalves $(<4 \mathrm{~mm})$, were fitted to a non-linear equation of a one-phase exponential decay in order to describe the gradual displacement of bivalves inside the experimental plots. Despite some variability (i.e. goodness of fit: $\mathrm{r}^{2}=0.5335$ to 0.8150 ) and few data points over time, the fit converged on a best-fit curve for all size-classes (Table 4, Fig. 4). The $<1 \mathrm{~mm}$ bivalves had an estimated half-life of $17.4 \mathrm{~h}$, whereas 1-4 mm bivalve displacement rates were considerably slower, with half-lives of $31.5 \mathrm{~h}$ (Table 4 ).

We estimated diffusion coefficients from the markrecapture data by measuring the rate of displacement from the quadrats. This was done after the analysis showing there was no transport of bivalves in any specific direction (see next paragraph).

Using simple diffusion models, such as random-walk modelling, we can make predictions on how far bivalves travel after being displaced. These diffusion rates were calculated using displacement rates within the quadrats. Estimated diffusion rates were $21 \mathrm{~cm} \mathrm{~h}^{-1}$ for $<1 \mathrm{~mm}$ post larvae and $12 \mathrm{~cm} \mathrm{~h}^{-1}$ for $1-4 \mathrm{~mm}$ juveniles (Table 5). Based on these diffusion rates we predicted that $<1 \mathrm{~mm}$ bivalves would travel/disperse (i.e. crossing times) between 50 and $100 \mathrm{~cm}$ within one tidal cycle and $500 \mathrm{~cm}$ within $24 \mathrm{~d}$ (predicted for the first arriving individuals). Corresponding values for the larger juvenile bivalves would be between 25 and $50 \mathrm{~cm}$ within 1 tidal cycle, whereas $500 \mathrm{~cm}$ would be reached in $73 \mathrm{~d}$ (1736 $\mathrm{h}_{\text {; }}$ Table 5). Expressed as the median distance travelled, post-larvae would reach $49 \mathrm{~cm}$ and juveniles $28 \mathrm{~cm}$ within the first tidal cycle (Table 5).

\section{Observed bivalve dispersal and comparisons with sediments}

The dispersal of bivalves was monitored along 4 orthogonal axes stretching out from each of the 3 quadrats (Fig. 1d). As noted for the tracer sediment, no directional movement was recorded. Thus the 4 different axes were pooled as 1 replicate for each quadrat on each sampling date. No consistent patterns of dispersal were detected for $<1 \mathrm{~mm}$ bivalves. The number of recaptured individuals was low in this size-class, and on average between 1 and 5 individuals were recaptured at each point along the sampled gradient (Fig. 5). No clear trend was detected, with $<1 \mathrm{~mm}$ bivalves occurring evenly along the whole gradient, indicating dispersal beyond the sampled gradient within the first tidal cycle. The distributional patterns of post-larvae 
Table 5. Predicted diffusion rates using a random walk model, the median distance travelled as a function of time, and estimated crossing times of the first arrivals for post-larvae and juveniles and all bivalves less than $4 \mathrm{~mm}$ combined

\begin{tabular}{|lrrr|}
\hline & $\begin{array}{c}\text { Total } \\
(<4 \mathrm{~mm})\end{array}$ & $\begin{array}{r}\text { Post-larvae } \\
(<1 \mathrm{~mm})\end{array}$ & $\begin{array}{r}\text { Juveniles } \\
(1-4 \mathrm{~mm})\end{array}$ \\
\hline Diffusion rates $\left(\mathrm{cm} \mathrm{h}^{-1}\right)$ & 20 & 21 & 12 \\
Median distance travelled (cm) & & & \\
$12 \mathrm{~h}(\mathrm{~T} 1)$ & 46.6 & 49.0 & 28.0 \\
$36 \mathrm{~h}(\mathrm{~T} 2)$ & 80.9 & 84.9 & 48.5 \\
$60 \mathrm{~h}(\mathrm{~T} 3)$ & 103.8 & 109.0 & 62.3 \\
Crossing time (h) & & & \\
$25 \mathrm{~cm}$ & 1.6 & 1.4 & 4.3 \\
$50 \mathrm{~cm}$ & 6.3 & 5.7 & 17.4 \\
$100 \mathrm{~cm}$ & 25.0 & 22.7 & 69.4 \\
$200 \mathrm{~cm}$ & 100.0 & 90.7 & 277.8 \\
$500 \mathrm{~cm}$ & 625.0 & 566.9 & 1736.1 \\
& & & \\
\hline
\end{tabular}

The number of 1-4 mm bivalves recaptured along the gradient was also low, with an average of only about 1 to 2 individuals recaptured along the sampled gradient at any time (Fig. 5). The distributional pattern along the gradient was significantly different than the sediment, except at T2 (Table 6). This suggests that, in contrast to the $<1 \mathrm{~mm}$ size-class, the 1-4 $\mathrm{mm}$ bivalves appear to have limited mobility when the combined wave and current disturbances are weak. Higher concentrations of tracer sediment were found close to the quadrat at T2 after the period of calm weather conditions (and limited sediment transport), compared to T1 and T3 (Fig. 3). The distributional pattern of 1-4 mm bivalves differed significantly over time, with T2 differing from

and sediment were significantly different over the whole study period (Table 6). Significant changes also occurred in the distributional pattern of $<1 \mathrm{~mm}$ bivalves over time: T2 was significantly different from T1 $\left(\chi^{2}=7.71, \mathrm{p}<0.05\right)$ and T3 $\left(\chi^{2}=17.51, \mathrm{p}<0.001\right)$, whereas no significant differences were recorded between T1 and T3. Although differences were recorded in how bivalves and sediment were dispersed along the sampled gradient at different times, no consistent pattern could be detected.

The predictions from the random walk modelling appreciably underestimated the distance moved when comparing with our observed data (cf. Fig. 5). Random walk modelling predicted the first arrivals would reach $100 \mathrm{~cm}$ from the experimental plot only after $23 \mathrm{~h}$ and that the median distances travelled would be $49 \mathrm{~cm}$ within T1, and $109 \mathrm{~cm}$ within T3.

Table 6. Results of chi-square analysis for comparisons of the distributional pattern of tracer sediment, different size-classes of bivalves irrespective of species, and post-larvae and juveniles of Macomona liliana and Austrovenus stutchburyi. Mac$\mathrm{pl}=M$. liliana post-larvae, Mac-juv $=M$. liliana juveniles, Aus-pl = A. stutchburyi post-larvae, Aus-juv = A. stutchburyi juveniles. ${ }^{*} \mathrm{p}<0.05,{ }^{* *} \mathrm{p}<0.01,{ }^{* * *} \mathrm{p}<0.001$, ns $=$ not significant

\begin{tabular}{|c|c|c|c|}
\hline & $\mathrm{T} 1$ & $\mathrm{~T} 2$ & T3 \\
\hline Sediment vs post-larvae & $* *$ & $* * *$ & $* * *$ \\
\hline Sediment vs juveniles & ${ }^{* *}$ & ns & ${ }^{* *}$ \\
\hline Sediment vs Mac-pl & $* * *$ & ns & $* * *$ \\
\hline Sediment vs Mac-juv & $* * *$ & ns & $* * *$ \\
\hline Sediment vs Aus-pl & $*$ & $* * *$ & $* * *$ \\
\hline Sediment vs Aus-juv & ns & ** & $* * *$ \\
\hline Mac-pl vs Aus-pl & ns & $* * *$ & ns \\
\hline Mac-juv vs Aus-juv & $* * *$ & $*$ & $* * *$ \\
\hline
\end{tabular}

both T1 $\left(\chi^{2}=27.74, \mathrm{p}<0.001\right)$, and T3 $\left(\chi^{2}=17.58, \mathrm{p}<\right.$ 0.001 ; Table 6$)$. As noted for the smaller post-larvae $(<1 \mathrm{~mm})$, no consistent pattern in the distribution along the gradient was detected for the 1-4 mm bivalves.

Sufficient numbers of Macomona liliana and Austrovenus stutchburyi were found outside the quadrats to allow for species-specific comparisons of the distribution of bivalves and sediment. Low numbers of both species were recaptured along the sampled gradient (Fig. 6). On average, 1 to $3 \mathrm{M}$. liliana individuals and

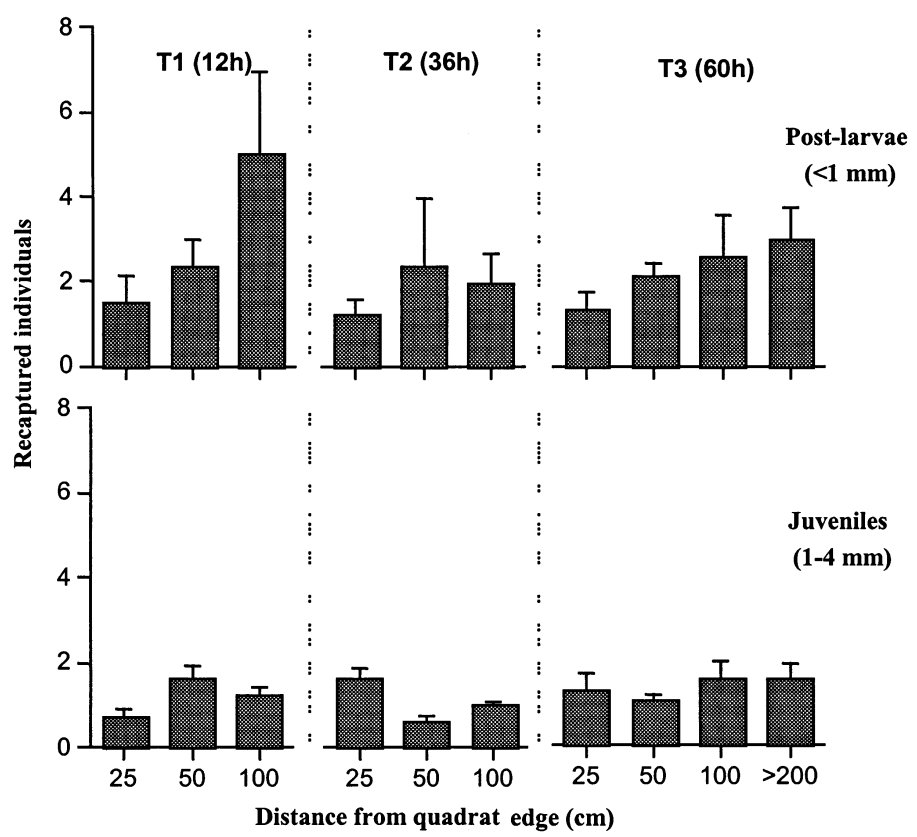

Fig. 5. Recaptured bivalves of the $<1 \mathrm{~mm}$ and $1-4 \mathrm{~mm}$ sizeclasses along a gradient away from the quadrat edge. $\mathrm{T} 1=$ $12 \mathrm{~h}$ following the experimental setup; $\mathrm{T} 2=36 \mathrm{~h}$; $\mathrm{T} 3=60 \mathrm{~h}$. Number of individuals are average values for all biological quadrats, pooled over all directions 


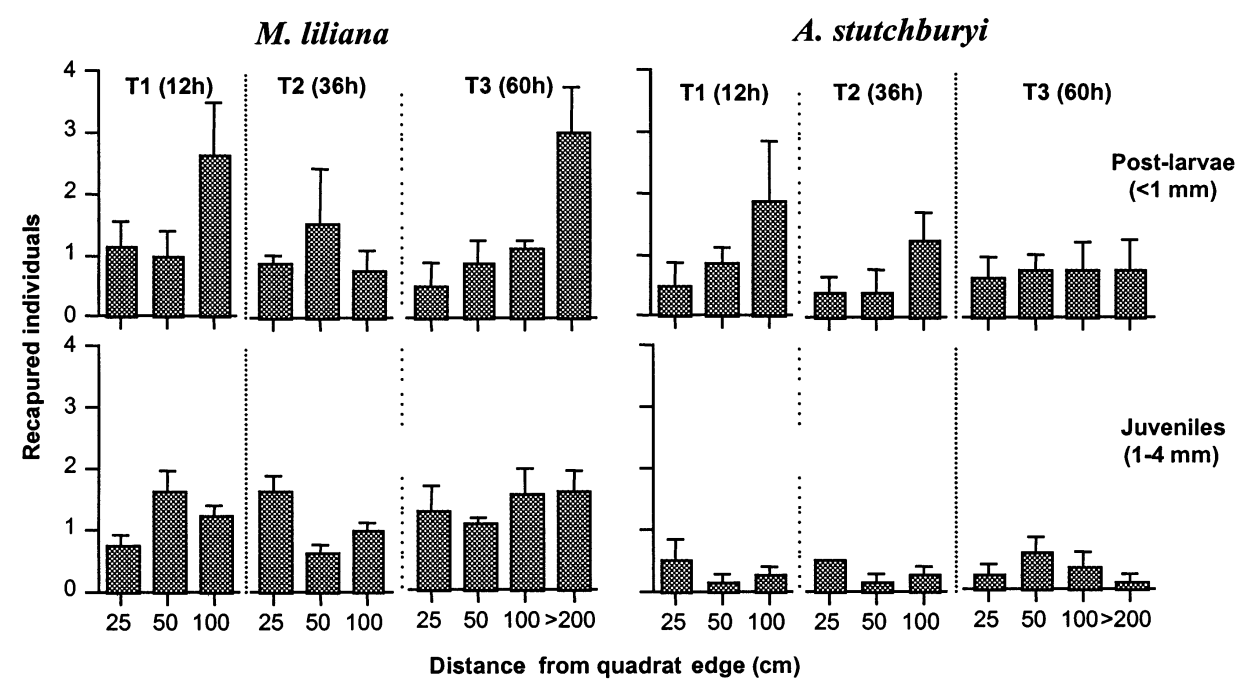

Fig. 6. Recaptured Macomona liliana and Austrovenus stutchburyi belonging to the $<1 \mathrm{~mm}$ and 1-4 $\mathrm{mm}$ size-classes in a gradient away from the quadrat edge. $\mathrm{T} 1=12 \mathrm{~h}$ following the experimental setup; $\mathrm{T} 2=36 \mathrm{~h}$; $\mathrm{T} 3=60 \mathrm{~h}$. Number of individuals are average values for all biological quadrats, pooled over all directions

1 to 2 A. stutchburyi individuals were recaptured (Fig. 6). The distribution of M. liliana post-larvae and juveniles was significantly different from the sediment at T1 and T3, but not at T2 (Table 6). This was in contrast with the results when all post-larvae $(<1 \mathrm{~mm})$, irrespective of species, were treated together (Table 6). The distribution of A. stutchburyi was significantly different from the sediment at all times, except for juveniles at $\mathrm{T} 1$ (Table 6).

\section{DISCUSSION}

Our results show that juvenile bivalves dispersed over scales of meters within one tidal cycle. Modelling the half-life of juvenile bivalve retention within the $0.25 \mathrm{~m}^{2}$ experimental plots, using radioactive decay equations, provided insight into the local persistence of individuals. These models indicate that for post-larval $(<1 \mathrm{~mm})$ bivalves $50 \%$ of the individuals present at the initiation of the experiment will be lost from the plot within the first $17.4 \mathrm{~h}$ (Fig. 4). Juvenile (1-4 mm) bivalves persist longer with $50 \%$ of the individuals present at the start of the experiment resident in the experimental plots up to $31.5 \mathrm{~h}$ after the initiation of the experiment. For all bivalves $(<4 \mathrm{~mm})$ the estimated half-life of residence with the experimental plot is 24.8 h. These radioactive decay models assume a monotonic decrease in the density of bivalves resident in the experimental plots at the start of the experiment. However, displacement of the juvenile bivalves only occurs when the site is immersed (35\% of time) and thus the potential for dispersal is even greater than it appears at first glance. As rates of dispersal will be markedly influenced by the day-to-day variations in hydrodynamic conditions on the sandflat, this analysis provides new insight into the transitory nature of individuals occurring at a given point in time on the sandflat and the size-dependence of dispersal.

\section{The dynamic sandflat environment}

Although the intertidal sandflats of the Manukau Harbour represent a dynamic sedimentary environment, this experiment was conducted during a calm period. The DOBIE wave gauge allowed us to describe accurately the wave climate during the course of the experiment. The largest waves recorded by DOBIE were only $15 \mathrm{~cm}$ high with a period of $2.6 \mathrm{~s}$. For most of the study, waves ranged in height between 3 and $11 \mathrm{~cm}$ (median wave). Waves of this size are commonly observed over many sandflats, indicating that juvenile bivalves living near the sediment surface have to cope with an environment characterised by a fluid 3-dimensional substrate. The potential for waves to influence dispersion and displacement of juvenile bivalves on the sandflat is related to the interaction between small waves and tidal currents. On this sandflat, peak tidal currents (maximum $22 \mathrm{~cm} \mathrm{~s}^{-1}$ ) are incapable of eroding bottom sediments, but when combined with near-bed orbital currents generated by small wind waves (wave height $>6 \mathrm{~cm}$ ) particle transport is readily initiated (Bell et al. 1997). This interaction emphasises the importance of wave climate, as well as tidal flows, for both the physical and biological processes occurring on sandflats. Sediment bedload transport corresponding to over $100 \mathrm{~kg} \mathrm{~m}^{-2} \mathrm{~d}^{-1}$ was recorded on the first and third sampling occasions, when winds blew from the west to southwest over the maximum fetch for the study site. Virtually no sediment bedload transport was recorded on the second sampling occasion when wind 
waves were absent (i.e. only $0.6 \mathrm{~kg} \mathrm{~m}^{-2} \mathrm{~d}^{-1}$ ). By the end of the experiment tracer sediments had been transported a maximum distance of $2.3 \mathrm{~m}$ from the plots, indicating lower net rates of sediment movement than bivalve movement. No specific directional transport was detected, rather sediment appeared to diffuse evenly in all directions from the experimental plots (Fig. 2). The pattern of sediment transport is a result of a complex interaction between wind, waves, wind-tide interactions and tidally varying water depth. The interaction of tidal and wave-generated currents, together with transient particle resuspension, means that the residual direction of transport is highly dependent on the particular combination of conditions that occur in any given period.

\section{Dispersal of bivalves-passive and active mechanisms}

Previous studies of dispersal have measured gross population fluxes and have not attempted to determine actual dispersal rates or distances moved by individuals in the field. The main reason for the lack of studies on actual dispersal rates and patterns is the crypsis of these animals, which makes their study difficult and arduous. The majority of these small bivalves are similar in size to the sand grains on the sandflat (juvenile bivalves range in size from 0.25 to $4 \mathrm{~mm}$ ), and are therefore difficult to observe in situ. Further problems arise due to their low abundances and patchy distribution in space and time. In our study these problems, the labour-intensive technique used and the expected rapid diffusion of marked bivalves meant that replication and sample distances were necessarily limited. The scale over which we measured dispersal was smaller than that over which they actually moved. Despite these shortcomings, and the fact that no clear dispersal patterns were detected, we feel that the results have significant implications as they both demonstrate the transient nature of juvenile bivalves on sandflats and also point at the importance of developing techniques that facilitate the study of these minute animals.

The number of re-captured bivalves outside the quadrat was variable and low (Fig. 5) partly due to their rapid turnover and transport over the sandflat, and partly due to the limitations of our experimental design and the power of the data. Our results suggest that both $<1 \mathrm{~mm}$ post-larvae and 1-4 mm juveniles can disperse further than $100 \mathrm{~cm}$ within the first $12 \mathrm{~h}$ (T1). By the end of the experiment $(60 \mathrm{~h}, \mathrm{~T} 3)$ individuals were recaptured further than $2 \mathrm{~m}$ away from the experimental plots. At T2 (36 h), the highest numbers of re-captured 1-4 $\mathrm{mm}$ bivalve individuals were found closest to the quadrat (Fig. 5), matching the pattern of the sediments. Although the larger and heavier juvenile (1-4 mm) bivalves behaved more like passive particles, they still only matched the dispersal pattern of the sediment at T2 when very little sediment transport occurred.

Generally, bivalve displacement from the experimental plots was decoupled from sediment movement, suggesting a role for active dispersal behaviour. Large differences were recorded in fall velocities for different size-classes of bivalves, but they all had higher fall velocities compared to that of sand (Table 3). Passive re-suspension of the lighter sediment particles should occur before that of the bivalves, further supporting active dispersal in the movement of juvenile bivalves. However, the species-specific analyses of Macomona liliana and Austrovenus stutchburyi emphasise differences in the dispersal ability of these 2 species. These observations are consistent with earlier studies that inferred relative mobility from dynamic spatial distributions (Hewitt et al. 1996, 1997a, Legendre et al. 1997). The lack of evidence for directional movement by bivalves and sediments suggested that bivalves might exhibit dispersal patterns best explained by Brownian motion. However, predictions based on random walk modelling yielded underestimates of the distances travelled by bivalves, suggesting that using an average diffusion rate for these models was inadequate. Irrespective of whether dispersal is passive or active, net effects are likely to correlate with the hydrodynamic regime. For juvenile bivalves restricted to living near the sediment surface, passive dispersal must dominate when boundary shear stresses are high. Emerson \& Grant (1991) showed a positive correlation between bedload transport and faunal dispersal. Juvenile bivalves cannot maintain their position by burrowing once sediment transport has been initiated (Roegner et al. 1995). Previous work in the Manukau has also illustrated the importance of wind wave disturbance and bedload transport as factors affecting the dispersal of bivalves (Commito et al. 1995a, Hewitt et al. 1996, 1997, Grant et al. 1997, Turner et al. 1997). Commito et al. (1995b) demonstrated bivalve movement to be positively correlated both to wind conditions and water velocity, as well as sediment transport, but also found higher rates of bivalve movement ( $M$. liliana) than expected, based on rates of sediment displacement. Turner et al. (1997) confirmed these results, showing a weak correlation between sediment transport and M. liliana dispersal (suggesting active dispersal behaviour), but a strong relationship with $A$. stutchburyi dispersal. Thus the effects of the physical variables on dispersal and subsequent observed faunal distributions are both size and species dependent.

Active post-settlement dispersal in some juvenile bivalves is aided by the alignment of the bivalve to the 
current and by the production of thin mucous threads that enable them to be lifted from the sediment surface into the water column (Sigurdsson et al. 1976, Butman 1987, Sörlin 1988, Beukema \& de Vlas 1989, Armonies 1992, Cummings et al. 1993, 1995). Byssus drifting facilitates the potential to disperse over large spatial scales, e.g. 1 to $10^{4} \mathrm{~m}$ (Beukema \& de Vlas 1989, Armonies 1996). In the tidal flat environment there is a continuous change in the environmental conditions and in the inter- and intra-specific interactions the bivalves experience. Active behavioural mechanisms for these minute animals may be triggered by cues operating at the scales of cm's (e.g. presence of adult conspecifics or biogeochemical cues).

\section{Implications for the study of sandflat ecology and for sampling benthos}

Recognising the importance of mobility and the potential for low persistence of individuals at specific locations (e.g. experimental plots) has important implications for our ability to study the functioning of benthic communities. Spatial and temporal patterns of populations may appear persistent, with relatively stable population densities (Table 2), but simultaneously involve a dynamic component of dispersal with a more or less continuous turnover of individuals within the population (Fig. 4).

Disturbance/recovery processes are generally recognised to play an important role in the ecology of soft bottoms (Hall et al. 1994). Recovery patterns are dependent on the spatial scale of disturbance (Smith \& Brumsickle 1989, Thrush et al. 1996, Beukema et al. 1999) and can involve different types of colonists, larval stages and post-settled juveniles and adults. Conceptual models typically dictate that larval stages with good dispersal abilities will dominate when the scales of disturbance are large, whereas post-larval stages have a more important role when scales of disturbance are small (Günther 1992) and when larvae are scarce (outside main larval recruitment periods). Determining the relative importance of different types of colonists is essential, as demographic models indicate that the rate of recolonisation by post-larval stages can have a profound influence on recovery rates (Whitlatch et al. 1998). Thus, knowing the rate and dispersal ability of post-larval macrofauna is critical to predicting recovery and how this may vary with the spatial scale of disturbance.

Dispersal might be more important than mortality in the population dynamics of juvenile bivalves over small and meso spatial scales. Using scaling arguments and scope analysis of Macomona liliana, Schneider et al. (1997) showed that kinematic factors (e.g. dispersal) will dominate over demographic factors (e.g. recruitment or mortality) up to temporal scales of months and spatial scales of 100 s of meters. However, corresponding relationships for adults are on a temporal scale of years and a spatial scales of meters due to their less active dispersal. In spite of this, dispersal has not been studied as a factor driving local population and community dynamics (Palmer et al. 1996). Local interactions such as predation or competition might play an important role when dispersal rates are low (e.g. during low disturbance frequencies), but are likely to be overwhelmed by immigration and emigration when dispersal is high (Frid \& Townsend 1989, Sih \& Wooster 1994, Palmer et al. 1996). Englund (1997) emphasised the importance of carefully considering the movement potential of prey species over broad spatial scales and different habitats in order to gain a mechanistic understanding of predator-prey relationships, as post-settlement migration may compensate for local losses due to predation. A metapopulation or source-sink dynamics approach might be needed when turnover rates are high, as local populations may be open subunits within a network of patches connected through dispersal (Palmer et al. 1996). Ecological theory suggests that as more mobile species interact with a larger landscape mosaic than sedentary species (Milne 1992), highly mobile populations may be less sensitive to local spatial conditions (Kotliar \& Wiens 1990). Nevertheless, Hewitt et al. (1996, 1997a,b) demonstrated persistence in spatial patterns for $M$. liliana and Austrovenus stutchburyi in the Manukau Harbour at a number of scales, even over periods when movement of individuals of both species was recorded. Interactions of juveniles of both species with adult $M$. liliana have also consistently been demonstrated (Thrush et al. 1997, 2000). Thus, a more or less continuous displacement of individuals does not preclude local biological interactions from being demonstrably important.

Acknowledgements. We thank Stephanie Turner and Sabine Rodda for their help in the field and laboratory. An earlier version of the manuscript was improved by the helpful comments by Jan Beukema. The manuscript was also improved by the comments by Doug Miller and 3 anonymous reviewers. This research was funded by the Foundation for Research Science and Technology.

\section{LITERATURE CITED}

Ansell AD (1983) The biology of the genus Donax. In: McLachlan A, Erasmus, T (eds) Sandy beaches as ecosystems. Developments in hydrobiology. Dr W. Junk Publishers, The Hague, p 607-634

Armonies W (1992) Migratory rhythms of drifting juvenile molluscs in tidal waters of the Wadden Sea. Mar Ecol Prog Ser 83:197-206

Armonies W (1994a) Turnover of postlarval bivalves in sedi- 
ments of tidal flats in Königshafen (German Wadden Sea). Helgol Meeresunters 48:291-297

Armonies W (1994b) Drifting meio- and macrobenthic invertebrates on tidal flats in Königshafen: a review. Helgol Meeresunters 48:299-320

Armonies W (1996) Changes in the distribution of 0-group bivalves in the Wadden Sea: byssus-drifting releases juveniles from the constraints of hydrography. J Sea Res 35: 323-334

Baggerman B (1953) Spatfall and transport of Cardium edule L. Arch Néerl Zool 10:315-342

Bell RG, Hume TM, Dolphin TJ, Green MO, Walters RA (1997) Characterisation of physical environmental factors on an intertidal sandflat, Manukau Harbour, New Zealand. J Exp Mar Biol Ecol 216:11-31

Beukema JJ (1993) Successive changes in distribution patterns as an adaptive strategy in the bivalve Macoma balthica (L.) in the Wadden Sea. Helgol Meeresunters 47: 287-304

Beukema JJ, de Vlas J (1989) Tidal-current transport of thread-drifting postlarval juveniles of the bivalve Macoma balthica from the Wadden Sea to the North Sea. Mar Ecol Prog Ser 52:293-200

Beukema JJ, Flach EC, Dekker R, Starink M (1999) A longterm study of the recovery of the macrozoobenthos on large defaunated plots on a tidal flat in the Wadden Sea. J Sea Res 42:235-254

Bonsdorff E (1983) Recovery potential of macrozoobenthos from dredging in shallow brackish waters. Oceanol Acta No Spec 27-32

Bonsdorff E, Norkko A, Boström C (1995) Recruitment and population maintenance of the bivalve Macoma balthica (L.) - factors affecting settling success and early survival on shallow sandy bottoms. In: Eleftheriou A, Smith C, Ansell A (eds) Biology and ecology of shallow coastal waters. Olsen \& Olsen, Fredensborg, p 253-260

Butman CA (1987) Larval settlement and soft-sediment invertebrates: the spatial scales of pattern explained by active habitat selection and the emerging role of hydrodynamical processes. Oceanogr Mar Biol Annu Rev 25:113-165

Commito JA, Currier CA, Kane LR, Reinsel KA, Ulm IM (1995a) Dispersal dynamics of the bivalve Gemma gemma in a patchy environment. Ecol Monogr 65:1-20

Commito JA, Thrush SF, Pridmore RD, Hewitt JE, Cummings VJ (1995b) Dispersal dynamics in a wind-driven benthic system. Limnol Oceanogr 40:1513-1518

Cummings VJ, Pridmore RD, Thrush SF, Hewitt JE (1993) Emergence and floating behaviours of post-settlement juveniles of Macomona liliana (Bivalvia: Tellinacea). Mar Behav Physiol 24:25-32

Cummings VJ, Pridmore RD, Thrush SF, Hewitt JE (1995) Post-settlement movement by intertidal benthic macroinvertebrates: do common New Zealand species drift in the water column? NZ J Mar Freshw Res 29:59-67

Dayton PK (1994) Community landscape: scale and stability in hard bottom marine communities. In: Giller PS, Hildrew AG, Raffelli DG (eds) Aquatic ecology: scale, pattern and process. Blackwell Scientific Publications, London, p 289-332

Dolphin TJ, Hume TM, Parnell KE (1995) Sedimentary and oceanographic processes on a sandflat in an enclosed sea, Manukau Harbour, New Zealand. Mar Geol 128:169-181

Emerson CW, Grant J (1991) The control of soft-shell clam (Mya areanaria) recruitment on intertidal sandflats by bedload sediment transport. Limnol Oceanogr 36:1288-1300

Englund G (1997) Importance of spatial scale and prey movements in predator caging experiments. Ecology 78: 2316-2325
Frid CLJ (1989) The role of recolonisation processes in benthic communities, with special reference to the interpretation of predator-induced effects. J Exp Mar Biol Ecol 126: 163-171

Frid CLJ, Townsend CR (1989) An appraisal of the patch dynamics concept in stream and marine benthic communities whose members are highly mobile. Oikos 56: 137-141

Grant J, Turner SJ, Legendre P, Hume TM, Bell RG (1997) Patterns of sediment reworking and transport over small spatial scales on an intertidal sandflat, Manukau Harbour, New Zealand. J Exp Mar Biol Ecol 217:33-50

Green MO, KP Black (1999) Suspended-sediment reference concentration under waves: field observations and critical analysis of two predictive models. Coastal Engineering 38: $115-141$

Günther CP (1992) Dispersal of intertidal invertebrates: a strategy to react to disturbances of different scales? Neth J Sea Res 30:45-56

Hall SJ, Raffaelli DG, Thrush SF (1994). Patchiness and disturbance in shallow water assemblages. In: Giller PS, Hildrew AG, Raffaelli DG (eds) Aquatic ecology: scale, pattern and process. Blackwell Scientific Publications, London, $\mathrm{p}$ 333-375

Hamilton WD, May RM (1977) Dispersal in stable habitats. Nature 269:578-581

Hansson L (1991) Dispersal and connectivity in metapopulations. Biol J Linn Soc 42:89-103

Hewitt JE, Thrush SF, Cummings VJ, Pridmore RD (1996) Matching patterns with processes: predicting the effect of size and mobility on the spatial distributions of the bivalves Macomona liliana and Austrovenus stutchburyi. Mar Ecol Prog Ser 135:57-67

Hewitt JE, Pridmore RD, Thrush SF, Cummings VJ (1997a) Assessing the short-term stability of spatial patterns of macrobenthos in a dynamic estuarine system. Limnol Oceanogr 42:282-288

Hewitt JE, Legendre P, McArdle BH, Thrush SF, Bellehumeur C, Lawrie S (1997b) Identifying relationships between adult and juvenile bivalves at different spatial scales. J Exp Mar Biol Ecol 216:77-98

Holt RD (1990) The micro-evolutionary consequences of climate change. TREE 5:311-315

Howard RK (1985) Measurements of short-term turnover of epifauna within seagrass beds using an in situ staining method. Mar Ecol Prog Ser 22:163-168

Ims RA (1995) Movement patterns related to spatial structure. In: Hansson L, Fahrig L, Merriam G (eds) Mosaic landscapes and ecological processes. Chapman \& Hall, London, $\mathrm{p}$ 85-101

Jablonski D (1986) Larval ecology and macroevolution in marine invertebrates. Bull Mar Sci 39:565-587

Jaklin S, Günther CP (1996) Macrobenthic driftfauna of the Gröninger Plate. Senckenb Marit 26:127-134

Kareiva P (1986) Patchiness, dispersal, and species interactions: consequences for communities of herbivorous insects. In: Diamond J, Case TJ (eds) Community ecology. Harper \& Row, New York, p 192-206

Kinsman B (1984) Wind waves: their generation and propagation on the ocean surface. Dover Publications, New York

Kotliar NB, Wiens JA (1990) Multiple scales of patchiness and patch structure: a hierarchical framework for the study of heterogeneity. Oikos 59:253-260

Legendre P, Thrush SF, Cummings VJ, Dayton PK, Grant J, Hewitt JE, Hines AH, McArdle BH, Pridmore RD, Schneider DC, Turner SJ, Whitlatch RB, Wilkinson MR (1997) 
Spatial structure of bivalves in a sandflat: scale and generating processes. J Exp Mar Biol Ecol 216:99-128

Levin L (1990) A review of methods for labeling and tracking marine invertebrate larvae. Ophelia 32:115-144

Martel A, Chia FS (1991) Drifting and dispersal of small bivalves and gastropods with direct development. J Exp Mar Biol Ecol 150:131-147

McLachlan A (1983) Sandy beach ecology-a review. In: McLachlan A, Erasmus T (eds) Sandy beaches as ecosystems. Developments in hydrobiology. Dr W. Junk Publishers, The Hague, p 321-388

Miller MC, McCave IN, Komar PD (1977) Threshold of sediment motion under unidirectional currents. Sedimentology 24:507-527

Milne BT (1992) Spatial aggregation and neutral models in fractal landscapes. Am Nat 139:32-54.

Nielsen P (1992) Coastal bottom boundary layers and sediment transport. World Scientific, Singapore

Okubo A (1980) Diffusion and ecological problems: mathematical models. Lecture notes in biomathematics 10 . Springer Verlag, Heidelberg

Palmer MA, Allan JD, Butman CA (1996) Dispersal as a regional process affecting the local dynamics of marine and stream benthic invertebrates. TREE 11:322-326

Pridmore RD, Thrush SF, Hewitt JE, Roper DS (1990) Macrobenthic community composition of six intertidal sandflats in Manukau Harbour, New Zealand. NZ J Mar Freshw Res 24:81-96

Pridmore RD, Thrush SF, Wilcock RJ, Smith TJ, Hewitt JE, Cummings VJ (1991) Effect of the organochlorine pesticide technical chlordane on the population structure of suspension and deposit feeding bivalves. Mar Ecol Prog Ser 76:261-271

Pulliam HR (1988) Sources, sinks and population regulation. Am Nat 132:652-661

Reise K (1985) Tidal flat ecology, Springer Verlag Heidelberg

Roegner C, Andre C, Lindegarth M, Eckman JE, Grant J (1995) Transport of recently settled soft-shell clams (Mya arenaria) in laboratory flume flow. J Exp Mar Biol Ecol 187:13-26

Rutherford E (1900) A radioactive substance emitted from thorium compounds. Philosophical Magazine, Series 5, 49: $1-14$

Savidge WB, Taghon GT (1988) Passive and active components of colonisation following two types of disturbance on intertidal sandflat. J Exp Mar Biol Ecol 115:137-155

Scheltema RS (1986) On dispersal and planktonic larvae of benthic invertebrates: an eclectic overview and summary of problems. Bull Mar Sci 39:290-322

Schneider DC, Walters R, Thrush SF, Dayton PK (1997) Scaleup of ecological experiments: density variation in the mobile bivalve Macomona liliana. J Exp Mar Biol Ecol 216:129-152

Editorial responsibility: Otto Kinne (Editor),

Oldendorf/Luhe, Germany
Shull DH (1997) Mechanisms of infaunal polychaete dispersal and colonization in an intertidal sandflat. J Mar Res 55: 153-179

Sigurdsson JB, Titman CW, Davies PA (1976) The dispersal of young post-larval bivalve molluscs by byssus threads. Nature 262:386-387

Sih A, Wooster DE (1994) Prey behaviour, prey dispersal and predator impacts on stream prey. Ecology 75:1199-1207

Smith CR, Brumsickle SJ (1989) The effect of patch size and substrate isolation on colonization modes and rates in an intertidal sediment. Limnol Oceanogr 34:1263-1277

Sörlin T (1988) Floating behaviour in the tellinid bivalve Macoma balthica (L.). Oecologia 77:273-277

Strathmann RR (1974) The spread of sibling larvae of sedentary marine invertebrates. Am Nat 108:29-44

Thrush SF, Pridmore RD, Hewitt JE, Cummings VJ (1992) Adult infauna as facilitators of colonization on intertidal sandflats. J Exp Mar Biol Ecol 159:253-265

Thrush SF, Whitlatch RB, Pridmore RD, Hewitt JE, Cummings VJ, Maskery M (1996) Scale-dependent recolonization: the role of sediment stability in a dynamic sandflat habitat. Ecology 77:2472-2487

Thrush SF, Cummings VJ, Dayton PK, Ford R, Grant J, Hewitt JE, Hines $\mathrm{AH}$, Lawrie SM, Pridmore RD, Legendre $\mathrm{P}$, McArdle BH, Schneider DC, Turner SJ, Whitlatch RB, Wilkinson MR (1997) Matching the outcome of small-scale density manipulation experiments with large scale patterns: an example of bivalve adult/juvenile interactions. J Exp Mar Biol Ecol 216:153-169

Thrush SF, Hewitt JE, Cummings VJ, Green MO, Funnell GA, Wilkinson MR (2000) The generality of field experiments: interactions between local and broad-scale processes. Ecology 81:399-415

Turner SJ, Grant J, Pridmore RD, Hewitt JE, Wilkinson MR, Hume TM, Morissey DJ (1997) Bedload and water-column transport and colonization processes by post-settlement benthic macrofauna: does infaunal density matter? J Exp Mar Biol Ecol 216:51-75

Van Rijn LC (1993) Principles of sediment transport in rivers, estuaries and coastal seas. Aqua Publications, Amsterdam

Weidner RT, Sells RL (1973) Elementary modern physics, 2nd edn. Allyn \& Bacon, Inc, Boston

Whitlatch RB, Lohrer AM, Thrush SF, Pridmore RD, Hewitt JE, Cummings VJ, Zajac RN (1998) Scale-dependent benthic recolonization dynamics: life stage-based dispersal and demographic consequences. Hydrobiologia 375/376: $217-226$

Wiens JA, Stenseth NC, Van Horne B, Ims RA (1993) Ecological mechanisms and landscape ecology. Oikos 66: $369-380$

Zar JH (1984) Biostatistical analysis. Prentice-Hall, Upper Saddle River, NJ

Submitted: January 17, 2000; Accepted: July 6, 2000

Proofs received from author(s): February 16, 2001 